\title{
"But They're Good for You!" ...The World of Horticulture as Brought to You by Popeye, Peter Rabbit, and Your Mother
}

\author{
Laura S. Sims \\ College of Human Ecology, University of Maryland, College Park, MD 20742
}

Many of you horticulturists; others are nutritionists or other health professionals. The horticulturists among us are fascinated by vascular systems, propagation and yield ratios, phytochemistryand. even, phloem. Nutritionists and other health professionals are more intrigued by discussions of omega-3 fatty acids. carbonic anhydrase, high-density lipoproteins. and even ratios of soluble to insoluble dietary fiber. What's missing . . People! What do consumers feel. think. and do about horticultural products-you know, plain ol' fruits and vegetables? That's my job-to share with you what we know about consumers. the missing link between the erudite discus sions you have between horticulturists and human health professionals.

Consumers have a real "mixed bag" of facts. half-truths, and conceptions about the role of fruits and vegetables in the diet. We have many to blame for this silly state of affairs, Aside from ourselves, we can blame Popular culture, the mass media, and even nursery rhymes. Let me explain. . .

Anthropologists, psychologists, sociologists have all gotten into the act. In reading anthropological literature such as that of Margaret Mead, one is often struck by the role that food plays-above and beyond the concept of simple human nutrition. We learn of the multiple roles of food in symbolic terms, its role in socialization of children, even as a measure of value exchange or currency. And. because in developing countries animal products are in such short supply, the role of horticultural products looms even larger.

Sociologists often talk of the role of certain foods in terms of their "shared meaning." What are the symbolic aspects of offering or sharing certain foods vs. others at social events? Have you ever thought of having a party without some kind of food and beverage refreshments? What about the "prestige value" of certain foods-what messages are sent by offering meatloaf to your boss rather than salmon or steak? Why are some foods identified as more "masculine" foods (e.g., the favored "meat and potatoes" descriptor combination) vs. "feminine" foods (why do we flinch when a gentleman orders a fruit salad for lunch?).

Psychologists also may consider the role of various foods in individual well-being. What does one choose to eat when feeling happy, depressed. bored, anxious? Pediatricians and nutritionists tell us we shouldn't, but who among us wasn't told as a child (or probably even hear ourselves saying as parents)-"Eat your beans or you don't get dessert."

We also have a whole array of associations wrapped up with various foods-vegetables may be "good for you." but probably wouldn't rate very high in one's own personal list of "taste goods." On the other hand, fruits are frequently blessed with high ratings on both attributes-something that tastes good that is also "good for you." Now, that's a find!

We even use various fruits and vegetables to denote certain attributes of psychological states. Just think what it means when one says. "Wow, what a tomato!" or "He's nutty." or "He's a real pea brain."

Just think of all the popular sayings that revolve around the as sociations we make with various fruits and vegetables:

"Carrots are good for your eyes." After all, you never saw Bugs Bunny wear glasses. did you?

"An apple a day keeps the doctor away..." Now we know that someone long ago knew much more about the physiological role of soluble fibers such as pectins in the diet, and it's only been in recent years that we've realized that such sayings may, in fact. have some scientific validity.

"Pretty as a peach." Was that saying invented in Georgia?

She's got a "peaches 'n' cream" complexion.

And, the ultimate compliment-"He's as patriotic as God, mother, and apple pie."

Let's also consider the various ways we have come to learn about food. What connotations or meanings still exist for us today? Think of all the folklore we were told as a child that includes references about various fruits and vegetables as a focal point of the story. Who among us has not been told over and over about "Jack 
and the Beanstalk", the "Princess and the Pea". or the adventures of Johnny Appleseed? And, who could resist downing the spinach in front of him (or her!) when watching the heroic exploits of Popeye as he battled the evil Bluto? Children's perceptions of food associations often emanate from such tales and may serve to inscribe certam foods with near-magical properties-surely eating enough spinach must empower one with the strength of a Popeye.

Even the nursery rhymes we tell our children foster such associ ations - Just think of. . .

"Peter, Peter, pumpkin eater..."

We know that Little Miss Muffet had her "curds and whey" but it was "Little lack Homer" who got to pull out the plum!

And here's one I wasn't familiar with:

Cantaloupes! Cantaloupes!

What is the price?

Eight for a dollar

And all very nice."

\section{Dietary guidance}

Nutritionists-and especially those of us in the field of nutrition education-start off with a fundamentally bad "rap". Everyone eats. therefore everyone is an expert on nutrition. Also, most of the dietary guidance is a guild-provoking enterprise. We feel "guilty" when we enjoy what we are consuming, hence the admonition, "It tastes good, therefore, it must be bad for me."

Nutritionists, both in the government and in the private sector, have been giving the American public advice about what to eat for nearly 100 years. We can trace the evolution of this dietary guidance as it corresponds loosely to an increased understanding of both human nutritional needs and the relationship of diet to health and disease.

Guides based on food groups have been published for well over 60 years. Between 1916 (when the USDA published its first dietary guidance plan) and the early 1950s. a variety of food guides were published by national, public, voluntary, and private organizations. All stressed a common theme-that the major dietary problem of the U.S. population was to balance the proportion of "protective" or nutrient-dense foods with foods that contribute primarily to the en ergy value of diets. This theme of balance in components of the total diet prevailed as a basis for food guides until the development of the Four Food Groups guide.

"Food for Fitness -- A Daily Food Guide", popularly referred to as the Basic Four or the Four Food Groups, was developed by USDA in the mid-1950s. The purpose of the guide, as stated by its authors, was to translate "what is known about nutritional require ments and about the composition of foods into a workable plan that will help the ordinary person select the kinds and amounts of foods that will give a nutritionally good diet". Clearly, the focus of these early dietary recommendations was the consumption of enough of the kinds of foods needed to provide needed amounts of nutrients and energy.

In the late 1960s. recommendations began to reflect concern about the excessive consumption of certain dietary components such as saturated fat and cholesterol and risk of some chronic diseases. In 1977, the Senate Select Committee on Nutrition and Human Needs, under the chairmanship of George McGovern. as one of its last acts, issued the document, "Dietary Goals for the U.S." This document, prepared in the minds of some more by lawyers that nutritionists. was a landmark statement in many ways. It was one of the first forms of dietary guidance that actually suggested quantitative goals for certain dietary components such as fat. cholesterol, salt, sugar, etc.. shown to be linked to the prevalence of certain chronic diseases.

In 1980, the USDA and the Dept. of Health and Human Services
(DHHS) collaborated to produce the "Dietary Guidelines for Americans". These were indeed less forceful than the "dietary goals" and were stated in nonquantitative terms. I remember at the time that such dietary advice was termed, "too little, too late". But, for many of us in the field, agreements between two government departments on certain dietary components thought to be associated with chronic disease was seen as a major accomplishment!

The second edition of the "Dietary Guidelines" was published in 1985 , and yet another group is now hard at work revising them for the third edition. An outside panel composed of nine scientists was appointed to review the original version and make recommendations for revision to the departments. The Committee's report generally reconfirmed the 1980 guidelines, with some changes in the accompanying text to clarify and include topics that had become more prominent since 1980 .

The seven dietary guidelines are: Eat a Variety of Foods; Maintain Desirable Weight; Avoid Too Much Fat, Saturated Fat and Cholesterol; Eat Foods with Adequate Starch and Fiber; Avoid Too Much Sugar; Avoid Too Much Sodium; If you Drink Alcohol, Do So in Moderation.

The advice contained in the dietary guidelines-the seven quali tative, directional statements confirming the role of certain dietary components in the diet-is considered by some nutritionists as "modest". The guidelines were intended to be applied together, in a total diet approach, for normal, healthy people. No single food was to be eliminated or designated as "good" or "bad". Instead, diets were to be planned based on the principles of variety, balance, and moderation.

In addition to dietary advice for the normal, healthy population, the federal government-particularly a couple of the more researchoriented National Institutes of Health-is now involved in a number of multimillion dollar informational campaigns for "at risk' population groups. Here the distinction between who is "normal" and who may be "at risk" becomes quite blurred.

One good example is the National Cholesterol Education Program, a major multimillion dollar informational campaign sponsored by the National Heart, Lung and Blood Institute. Guidelines for identifying the "at risk" group (those having serum cholesterol levels >240 mg) were released last year for the "Physicians' Panel", and recommendations from the "Population-based Panel" are expected next year.

In July 1988. the surgeon General's Report on "Diet and Health" was released. This report was published as both a 700-page "tome" for professionals, as well as a shortened Executive Summary version. Although the report had been 4 years in the making, the infor mational content of the book included very few, if any. controversial statements. However, any authoritative statement by the Surgeon General of the United States reaffirming a conclusive risk between particular dietary components and the risk of certain degenerative, chronic diseases cannot be dismissed lightly.

The dietary guidance game, however. is not one played only by USDA and DHHS in the federal government. One of the more interesting "alliances" competing for the attention of the food-buying consumer are the "Promotion Board" activities. Financed largely by food producers' fees and assessments, with oversight provided by the Agricultural Marketing Service (AMS) of the USDA, promotional activities currently exist for commodities such as beef, pork ("the other white meat"). dairy products, eggs, wheat, honey, water melon.

The government is certainly not the only-or even the predomi nant - actor in the dietary guidance arena. Voluntary health agencies. such as the American Cancer Society and the American Heart Association. are quite involved in activities that provide dietary guidance to the American public.

One of the more interesting "private sector" efforts to promote good nutrition is "Project Lean", now being developed under the support of the Kaiser Family Foundation. An advertising campaign. under the co-sponsorship of the Advertising Council, is being developed and will feature short spots for radio, TV, and print ads. Accompanying the advertising effort, are activities sponsored by a coalition of professional associations, 
voluntary health agencies. government groups and trade associations-including the Produce Marketing Assn., called "Partners for Better Health". The goal of this most ambitious effort is to encourage the American Public to consume a diet lower in fat.

How do these various sets of dietary recommendations compare? Are they offering comparable or conflicting advice to American consumers? Cronin and Shaw, two USDA nutritionists sought to answer this question; the results of their efforts appear in a paper published in Nutrition Today in Dec. 1988.

Several of these sets of recommendations are designed to provide general dietary advice, while others suggest dietary practices to reduce the risk of heart disease and cancer. Six of the organizations specifically recommend consuming a variety of foods to meet nutrient needs. Most make statements about moderating or reducing total fat in the diet. The recommendations about dietary fatty acids arc varied-from giving no recommendations at all to recommending the reduction or avoidance of too much saturated fat. Four organizations suggest reducing or avoiding too much dietary choles terol, but only the committee that established Dietary Goals and the AHA suggest specific levels. Recommendations about carbohydrates are difficult to summarize because the terminology is not consistent among the various reports. Seven organizations suggest either reducing or avoiding too much sodium or salt in the diet. and five suggest specific ranges or maximum levels.

A particular controversy currently looming on the horizon is whether or not the American public will be given quantitative or qualitative dietary advice-and what consumers will know what to do with it once they have it! A committee of the National Academy of Sciences/National Research Council, Food and Nutrition Board-the "Diet and Health" Committee-released a set of recom mendations in Mar. 1989 that called for Americans to eat $30 \%$ or less of calories as fat, $1<300 \mathrm{mg}$ of cholesterol daily, at least $55 \%$ of calories as carbohydrates (particularly "complex" carbohydrates), and no more than twice the RDA for protein. No big surprises, but certainly more quantifiable information for consumers to digest and chew!

The latest in ail this nutritional numerology is the long-awaited 10th ed. of the Recommended Dietary Allowances (RDSs) released in Nov. 1989 after a 4-year delay. There were no major surprises; The Washington Post published an article on 1 Nov. 1989. calling it "nothing really radical" and advised consumers to "use a little com mon sense and a lot of variety". While the quantitative recommendations were not really revolutionary. an RDA was set for the first time since 1941 for selenium and vitamin K. Calcium recommendations for young adults 18 to 24 years of age were set at $1200 \mathrm{mg}$. but no changes were made in the 800-mg allowance for women 25 years or older. For women between the ages of 11 and 50, the RDA were lowered from 18 to $15 \mathrm{mg}$ daily. The recommendation for vitamin $\mathrm{C}$ remained at $60 \mathrm{mg}$, except for smokers, who were advised to get at least $100 \mathrm{mg}$ because they process and eliminate this vitamin more quickly.

So, where does all of this leave us? In addition to current dietary recommendations-usually offered by governmental or public-sector organizations-consumers are bombarded by nutrition information delivered via the media. Indeed, surveys have documented that, while consumers may be more aware today of the diet-health link, many have become more confused than ever with all of the information on nutrition and diet that is available, much of it conflicting in its advice offered to consumers.

Least we oversell the positive role of increased consumer aware ness of nutrition. we must remember that other factors also exert a major influence on food choices. Taste, price, and ease of preparation are only three of a long List. Interestingly enough. recent surveys indicate that the nutrition and health kick among Americans may have peaked in the mid-1980s. but concern over obesity continues. Convenience in both shopping and food preparation has become a major factor in consumer buying decisions. I recently heard a presentation in which a researcher on consumer food behavior indicated that concern about nutrition has remained a constant; now consumers either choose on the basis of "taste" considerations (I call this the "Lean Cuisine-Dove Bar" form of food behavior) or "ease of preparation" or "convenience", a must for busy, duel-career families with children at home.

We all agree that quality, convenience, and health are among the top 10 "desirable" qualities in the food we consume. In a recent survey. American consumers were asked to define foods that are high in these three attributes. Food quality, consumers responded, is good taste, fresh, natural, nutritional, and name brand-in that order. The highest-quality convenience foods, they said. are frozen vegetables and cake mixes, also in that order. Healthy foods, on the other hand, are defined by consumers as nutritional, fresh, natural, and preservative-free.

But, have demographic changes coupled with increased consumer awareness of diet and health really made a difference in food consumption behaviors? You bet they have! A comparison of the results of the Nationwide Food Consumption Surveys conducted by the USDA in 1977 with results of the Continuing Survey of Food intakes by Individuals (CSFII) in 1985 show that changes that had taken place in that 8-year period. For women (the primary group studied), major increases were shown in consumption of skim or lowfat milk, carbonated soft drinks, meat as mixtures (e.g., spaghetti), and grain products. Declines were shown in the consumption of whole milk, meat, and eggs. Fruit and vegetable consumption was up-mainly in the form of fresh fruit and salads. An interesting irony is that. while consumption of fat from animal products has declined (less butter, less whole milk. less fat from meat, etc.), even nutrition-conscious consumers were piling on the fat in the form of salad dressings. table fats and spreads, as well as rich desserts.

Similar changes were shown in the diets of children 1 to 5 years of age, with some notable-perhaps "more healthful"- distinctions. Children's diets showed a major increase in the amount of vegetables and fruits consumed and a decline in the amount of carbonated beverages.

If we examine such dietary changes not just as these self-report data, but also from the view of agricultural "disappearance" data. the trends remain the same. Some of the most marked changes oc curred in the consumption of meat, poultry, and fish, where percapita consumption reached a record high in 1987. Of this total, consumption of red meat slacked off. poultry consumption climbed, and fish and seafood consumption remained fairly stable.

For horticulturists, let me describing changes in fruit and vegetable consumption. Sharp increases in the consumption of fresh noncitrus fruits-such as bananas, grapes. apples, avocados, straw berries-pushed per-capita fresh fruit consumption up $11.8 \mathrm{~kg}$ from 1972 to 1987 . for a total of $44.5 \mathrm{~kg}$. Imports have made a substantial contribution to this growth. United States fresh fruit imports have nearly doubled since 1970. In 1987, they accounted for more than half of the U.S. supply of fresh non-citrus fruits other than apples.

Total per-capita consumption of nine major commercial fresh vegetables hit $35.7 \mathrm{~kg}$ in 1987, $21 \%$ above the 1970 level. Between 1972 and 1987, tomatoes, onions and broccoli saw the biggest gains, of 1.8. 1.6. and $1.2 \mathrm{~kg}$, respectively. American also ate more asparagus, carrots. and cauliflower. Because of cutbacks in data collections. consumption estimates are no longer available for many of the fresh vegetables reported prior to 1982. including arti chokes. eggplant, cabbage, cucumber. garlic, green beans, and spinach. items that accounted for $28 \%$ of per-capita fresh vegetable consumption in 1981 . Tomatoes, with $74 \%$ of the market, were the \#1 canned vegetable in 1987. Sweet corn accounted for another $12 \%$. Per-capita consumption of potatoes have been relatively constant since 1972. as frozen potatoes have substituted for fresh. In 1987, Americans consumed an average of $55.8 \mathrm{~kg}$ per capita (farmweight basis). Of that, fresh market potatoes and frozen potatoes each accounted for 38\%; chips and shoestrings, $14 \%$; dehydrated and canned. the remaining $10 \%$.

The final point that I shall raise is the alarming trend of consumers who are losing trust in the safety and quality of our food supply. The Food Marketing Institute. the largest trade association of food chains, each year publishes a report called "Trends". in 
which consumers are surveyed about their attitudes and self-report ed practices. Not surprisingly, consumers reported that they wanted food that tastes good, is reasonably priced, nutritious, and safe to eat. However, the latter factor has emerged as increasingly impor tant.

When the FMI survey was taken in Jan. 1989, more than eight out of 10 persons surveyed said they were totally or very confident of the safety of food in supermarkets. Three months later, after publicity on Alar and the tampering of Chilean grapes, public confi dence dropped to $67 \%$. By late April. it recovered slightly, yet one of every four consumers remained doubtful of the safety of the food in stores.

Another alarming fact from the FMI survey was that more shoppers looked to consumer organizations than to the federal government for food safety information. Four out of 10 said they held themselves responsible for the safety of their food. but only half that number relied on federal regulation to protect them from food safety hazards.

While government has the major responsibility for food safety policy, consumers must learn about proper food handling techniques. Microbial contamination of food is a concern. although most media and consumer attention has been more focused on chemical issues. There are an estimated 80 million cases of enteric foodborne illness each year, most caused by consumption of contaminated dairy, meat poultry, and egg products. Consumers can protect themselves from microbial contaminants in almost every case by proper food handling techniques.

Coupled with consumers' distrust of the safety of the food supply is the pesticide problem. A major alarm in the eyes of consumers was sounded when a report from the Natural Resources Defense Council in Feb. 1989 alleged that children are at increased risk of developing cancer from consuming pesticide residues in fresh and processed fruits and vegetables. This report was soon fol- lowed by a Time magazine feature article entitled, "Watch Those Vegetables, Ma". with the following trailer, "Pesticide-laden produce may endanger your tots". Where are you when we need you Popeye. Johnny Appleseed. or Jack with your beanstalk?

FMI knows that the consumer's perception of the quality of fresh produce is the most important factor they use when it comes to choosing a supermarket in which to shop. In Mar. 1989, after all the pesticide scares, $44 \%$ of respondents to a Gallup telephone sur vey said they had cut purchases of apples; $41 \%$ cut purchases of vegetables. Sales of organic produce sky-rocketed. A survey conducted by researchers at the Univ. of California. Davis, found that $39 \%$ of respondents said organic foods are better than foods grown conventionally with chemicals and pesticides. These results, according to the investigators, indicated a distinct shift in consumer attitudes since the early 1970 s. With all of the current dietary advice to increase fresh fruit and vegetable consumption, is it no wonder that we are faced with a food-consuming public that is confused. alarmed, and angry?

The situation is grim. This serious dichotomy between advice to increase consumption of those very food products that also are seen by some consumers as "unsafe" must be addressed by leaders in business, government. the scientific community, the news media and others. In Fall 1989, the produce industry sent an urgent message to President Bush asking his administration to take steps to re build shattered consumer confidence in food safety.

I am delighted that NIH has agreed to fund a multi-million dol lar research program on horticulture and human health. Indeed, it is in areas like the pesticide and food safety issues coupled with the nutritional benefits of horticultural products that offer unique and fertile fields of collaborative endeavor between horticulturists and human nutritionists and other health professionals. My we move forward with collective wisdom in this increasingly important task. 